\title{
DAMPAK PEMBANGUNAN JALAN TOL TERHADAP FAKTOR SOSIAL, EKONOMI DAN LINGKUNGAN PADA USAHA BATIK DAN PERHOTELAN DI KOTA PEKALONGAN
}

\author{
Victorianus Aries Siswanto, Tri Pudji Wahjuningsih, Murtini \\ STMIK Widya Pratama Pekalongan, Jl Patriot No 25 Pekalongan Phone 427816, \\ Korespondensi : fixvictor@gmail.com
}

\begin{abstract}
The construction of the Trans Java toll road is a national program which is expected to have a positive impact on economic development for the Java region. Toll roads are built with the hope of reducing congestion as well as income of the state treasury. But on the other hand, the construction of this toll road raises new problems, namely reduced income, changes in the environment for batik traders, hotels, restaurants and other problems, because in the pantura area there are many small to medium-sized businesses that rely on business from visitors who pass through the northern coast road. For this reason, with the construction of the Trans Java Toll Road, it is necessary to examine whether the construction of the Trans Java Toll Road has had an impact on economic, social and environmental changes. By using purposive sampling a sample of 140 respondents was obtained. Respondents were drawn from batik businesses, batik consumers, hotels, hotel guests and the public. By using descriptive analysis the results of the study found that the greatest impact of toll road development is the economic impact. From questionnaire, 54.5\% of batik businesses stated that their businesses had decreased and $72.7 \%$ of respondents from hotels stated that their room rent had decreased. Whereas from the elements of batik buyers, hotel guests and the public, the construction of this toll road has had a positive impact. Recommendations from the results of this study can be given that the Pekalongan City Government needs to hold national level events, need to hold religious tourism periodically, need improvement and promotion of Pekalongan tourism, it needs to be assessed if it is proposed to build a batik shop in a rest area, canting pillars or landmarks in the road to the Pekalongan toll exit as well as the batik businesses asking for real and immediate action from the government with this economic impact.
\end{abstract}

Keywords: Trans java toll road, Toll road impact, Social factors, Economic factors and Environmental factors, Pekalongan city

\section{PENDAHULUAN}

Pembangunan jalan tol merupakan salah satu alternatif dalam mempercepat sarana transportasi, pariwisata, dan pertumbuhan ekonomi. Dengan adanya jalan tol maka kemacetan lalu lintas dapat dikurangi. Jalan tol juga dapat mempersingkat jarak dari satu kota ke kota lainnya. Pembangunan jalan tol Trans Jawa merupakan program nasional yang diharapkan memiliki dampak positif terhadap pembangunan ekonomi bagi daerah Jawa. Pembangunan jalan tol membutuhkan modal besar dan lahan untuk pembangunan tersebut. Jalan tol dibangun dengan harapan dapat mengurangi kemacetan juga sebagai pemasukan kas negara. Namun di sisi lain, pembangunan jalan tol ini memerlukan pembebasan lahan yang dimiliki masyarakat sekitar jalan tol tersebut.

Pembebasan lahan untuk keperluan jalan tol tentunya menimbulkan permasalahan baru. Banyak lahan persawahan yang terkena pembebasan lahan. Dengan hilangnya lahan kerja maka dapat berakibat pekerjaan berubah bahkan tidak bekerja sama sekali. Pembangunan jalan tol juga berpengaruh terhadap usaha-usaha masyarakat di daerah pantura. Rumah makan, sentra batik pasti terkena imbas dari adanya jalan tol ini. 
Jalan tol ini pasti membawa dampak, tidak hanya daerah namun masyarakat di daerah pantura yang digunakan untuk mencari nafkah. Secara pelan namun pasti masyarakat yang memiliki usaha mikro kecil dan menengah akan merasakan dampaknya dan terancam usahanya. Usaha itu seperti rumah makan, pusat jajan daerah, sentra batik, perhotelan dan sebagainya. Hal serupa juga terjadi pada pembangunan jalan tol Soker seperti yang diberitakan di suaramerdeka.com (22 Desember 2017) yang menyatakan bahwa dengan adanya jalan tol terjadi kemunduran ekonomi.

Berdasarkan pengamatan yang dilakukan oleh BI cabang Cirebon (kompasiana.com, 14 Desember 2018) sejak adanya jalan tol, menunjukkan $70 \%$ restoran tutup, 30\% usaha anjlok, $70 \%$ omzet SPBU turun. Kalau secara mikro, penjualan batik di Pekalongan menurun hingga 70\%, penjualan telor asin di Brebes turun lebih dari $50 \%$. Padahal di jalur pantura banyak usaha-usaha kecil hingga menengah. Pemerintah Daerah dan masyarakat tentu merasa khawatir dengan pembangunan jalan tol Trans Jawa ini. Mereka mengkhawatir karena dapat mengancam perekonomian daerah pantura, bahkan dapat menjadi "kota mati" karena tidak dilewati lagi. Pusat bisnis dan pariwisata dikhawatirkan tidak akan dilalui pengguna karena mereka lebih memilih jalan tol.

Pekalongan sebagai World City of Batik tentunya banyak sekali warga yang menggantungkan hidupnya pada usaha batik. Demikian juga usaha perhotelan yang berdiri di Kota Pekalongan. Sebagian usaha batik dan perhotelan terletak didaerah Pantura, dimana pendapatan mereka banyak didapat dari pengunjung yang melalui jalan tersebut. Namun dengan dibukanya jalan tol Trans Jawa, sebagian kendaraan akan lewat jalan tol. Maka perlu diteliti bagaimana dampak pembangunan jalan tol terhadap perekonomian, faktor sosial dan lingkungan para pedagang batik dan perhotelan di Kota Pekalongan ini.

\subsection{Rumusan Masalah}

Dari latar belakang tersebut maka permasalahan yang akan diulas dalam penelitian ini adalah :

a) Bagaimana respon penjual batik dan perhotelan atas pembangunan jalan tol Trans Jawa?

b) Bagaimana dampak sosial dari pembangunan jalan tol Trans Jawa bagi penjual batik dan perhotelan?

c) Bagaimana dampak ekonomi dari pembangunan jalan tol Trans Jawa bagi penjual batik dan perhotelan?

d) Bagaimana dampak lingkungan dari pembangunan jalan tol Trans Jawa bagi penjual batik dan perhotelan terhadap?

\subsection{Tujuan Penelitian}

Tujuan dari penelitian ini adalah untuk mengetahui respon dan dampak pembangunan jalan tol terhadap faktor sosial, ekonomi dan lingkungan pada usaha batik dan perhotelan di Pekalongan. Dari dampak yang diketahui ini dapat digunakan untuk pengambilan keputusan kebijakan-kebijakan maupun langkah-langkah yang perlu dilakukan demi perkembangan usaha batik dan perhotelan di Pekalongan.

\section{LANDASAN TEORI}

\subsection{Pengertian Jalan Tol}

Jalan tol merupakan jaringan jalan umum lintas alternatif dimana pengguna jalan wajib membayar tol. Pembangunan jalan tol dilakukan untuk memperlancar 
lalu lintas di daerah yang berkembang, pelayanan distribusi barang dan jasa untuk menunjang kebutuhan ekonomi serta meringankan beban dana pemerintah. (UU no 15 tahun 2005)

\subsection{Dampak Pembangunan Jalan Tol}

Pembangunan jalan tol Trans Jawa berdampak pada faktor sosial, faktor ekonomi dan faktor lingkungan.

\section{a) Faktor Sosial}

Faktor sosial adalah keadaan kehidupan masyarakat di suatu wilayah. Yang dimaksud faktor sosial dalam penelitian ini adalah segala sesuatu yang berkaitan dengan hubungan sosial antar masyarakat atau stakeholder yang terkena pembangunan jalan tol.

Adapun faktor sosial meliputi

1) Hubungan Jual beli

Hubungan jual beli di sini meliputi hubungan antara pembeli, penjual maupun stake holder / suplier bahan batik

2) Kemudahan marketing maupun pengiriman barang

Akses marketing maupun pengiriman barang baik bahan mentah maupun barang jadi

3) Keamanan dan Ketertiban

b) Faktor Ekonomi

Faktor ekonomi merupakan penggerak kehidupan sehari hari. Faktor ekonomi dalam penelitian ini meliputi pendapatan dan pembeli atau konsumen

Ada berbagai faktor ekonomi, meliputi

1) Pendapatan

Pendapatan berhubungan dengan bertambahnya pembeli atau pengunjung dan pemasukan

2) Kesempatan membuka usaha baru

3) Pelanggan baru

c) Faktor Lingkungan

Faktor lingkungan dalam penelitian ini merupakan kondisi lingkungan di sekitar tempat usaha. Faktor lingkungan meliputi :

1) Tempat usaha yang luas

2) Tempat parkir

3) Transportasi ke tempat usaha

\subsection{Penelitian Terdahulu}

Pada penelitian ini dilakukan kajian pustaka atau mereview penelitian sebelumnya sebagai bahan perbandingan dan untuk memperkaya perspektif dalam penelitian. Adapun hasil penelitian terdahulu yang relevan dengan penelitian ini yaitu:

a) Jurnal ilmiah dari Dhony Priyo Suseno dkk (2017) dengan judul Analisis Dampak Jalan Tol Terhadap Faktor Sosial, Ekonomi dan Lingkungan di Desa Kaligangsa Kulon Kabupaten Brebes didapatkan hasil bahwa adaya jalan tol Pejagan Pemalang sangat berdampak terhadap kehidupan masyarakat desa Kaligangsa Kulon. Besarnya dampak yang dirasakan masyarakat yang paling dominan adalah 
faktor sosial sebesar $34,454 \%$, kemudian faktor ekonomi $21,351 \%$ dan faktor lingkungan sebesar 13,913

b) Jurnal ilmiah dari Triana Rosalina Noor dkk dengan judul Analisis Dampak Sosial Ekonomi Pembangunan Jalan Tol Surabaya - Mojokerto didapatkan hasil bahwa pembangunan jalan tol tidak berpengaruh terhadap mata pencaharian kecamatan Wringinanom karena rata rata masyarakat bekerja sebagai petani.

\section{METODE PENELITIAN}

\subsection{Lokasi dan Waktu Pelaksanaan}

Lokasi penelitian yang digunakan untuk obyek penelitian adalah grosir Batik Setono, Kampung Batik Hayam Wuruk dan Perhotelan yang ada di Pekalongan. Adapun waktu pelaksanaan penelitian dilakukan sejak bulan Juli 2019 hingga November 2019

\subsection{Metode Pengumpulan Data}

Teknik pengambilan data yang digunakan adalah :

a) Wawancara

Dengan wawancara maka akan diperoleh gambaran umum persepsi penjual batik dan perhotelan tentang faktor sosial, ekonomi, dan lingkungan.

Adapun hasil rangkuman hasil wawancara pada saat monitoring dengan Bapak Muchsinin, SH manajer Hotel Istana pada tanggal 13 Agustus 2019 adalah sebagai berikut :

Tabel 1 Hasil Wawancara

\begin{tabular}{|c|c|c|}
\hline No & Pertanyaan & Jawaban \\
\hline 1 & $\begin{array}{l}\text { Dengan adanya jalan tol, apakah ada } \\
\text { dampak terhadap Perhotelan? }\end{array}$ & Ada, yaitu terjadi penurunan pendapatan \\
\hline 2 & $\begin{array}{l}\text { Harapan yang diinginkan stake holder agar } \\
\text { pendapatan dapat kembali seperti semula }\end{array}$ & $\begin{array}{l}\text { a. Pemerintah harus sering mengadakan } \\
\text { event event yang bersifat nasional agar } \\
\text { banyak orang yang datang ke } \\
\text { Pekalongan } \\
\text { b. Pemerintah lebih menggalakan pariwisata } \\
\text { yang ada di Pekalongan yaitu dengan } \\
\text { mempromosikan dan memperbaiki / } \\
\text { memperindah lokasi lokasi wisata yang } \\
\text { ada di Pekalongan } \\
\text { c. Sering diadakan wisata religi misal acara } \\
\text { Haul di Sapuro atau wisata religi dari } \\
\text { Habib Lutfi }\end{array}$ \\
\hline
\end{tabular}

b) Observasi

Observasi dilakukan dengan mengamati secara langsung di lokasi Grosir Setono, kampung batik Hayam Wuruk maupun perhotelan di Kota Pekalongan untuk mengetahui kondisi setelah adanya jalan tol.

Observasi dilakukan dengan mendatangi secara langsung dan berkeliling di toko toko batik selama beberapa hari dan hasil pengamatan terlihat memang pembeli batik tidak begitu banyak.

c) Kuesioner

Kuesioner dibagikan untuk mengetahui dampak pembangunan jalan tol dilihat dari faktor sosial, ekonomi dan lingkungan.

Pembagian kuesioner menggunakan teknik purposive sampling yaitu sampel diambil sesuai dengan ciri penelitian. 
Adapun kuesioner yang telah dibagikan meliputi :

1) Kuesioner untuk pengelola batik

Kuesioner yang dibagikan ke toko batik sejumlah 50. Pembagian dilakukan tanggal 2 Agustus 2019

2) Kuesioner untuk pembeli batik

Kuesioner yang dibagikan ke konsumen batik sejumlah 56 kuesioner. Pembagian kuesioner dilakukan tanggal 7 Agustus 2019

3) Kuesioner untuk pengelola hotel

Kuesioner hotel dibagikan ke 16 hotel di Pekalongan meliputi hotel bintang dan melati. Kuesioner dibagikan tanggal 13 Agustus 2019

4) Kuesioner untuk tamu hotel

Kuesioner yang dibagikan ke tamu hotel sejumlah 22 kuesioner. Kuesioner dibagikan tanggal 22 Agustus 2019

5) Kuesioner untuk masyarakat umum

Kuesioner yang dibagikan ke masyarakat sejumlah 70 kuesioner. Kuesioner dibagikan tanggal 28 Agustus 2019

\subsection{Metode Pengambilan Sampel}

Beberapa populasi penelitian ini termasuk Populasi yang tidak terbatas karena jumlahnya sulit ditentukan seperti pembeli batik, tamu hotel dan sebagainya. Salah satu teknik yang dapat menghitung sampel yang tidak terbatas adalah rumus dari Lemeshow.

Adapun rumus Lemeshow adalah sebagai berikut :

$$
\mathrm{n}=\frac{\mathrm{z}^{2} \cdot \mathrm{P}(1-\mathrm{P})}{\mathrm{d}^{2}}
$$

Keterangan :

$\mathrm{n}=$ jumlah sample

$\mathrm{z}=\mathrm{z}$ skor pada kepercayaan $95 \%=1,96$

$\mathrm{p}=$ maksimal estimasi $=0,5$

$\mathrm{d}=$ sampling error $10 \%$

$\mathrm{n}=\frac{1,96^{2} \cdot 0,5(1-0,5)}{0,1^{2}}$

$=96,04$ dibulatkan jadi 100

Jadi untuk pengambilan sampel minimal data yang harus diolah sebesar 100 responden.

Pada penelitian ini telah diambil sampel sebanyak 209 responden, namun setelah melalui uji validitas dan reliabilitas didapat data yang valid untuk diolah sebesar 140 data. Adapun rincinannya sebagai berikut :
a) Data Toko Batik sebanyak 44 responden
b) Data Hotel sebanyak 11 responden
c) Data Konsumen batik sebanyak 22 responden
d) Data Tamu hotel sebanyak 30 responden
e) Data Masyarakat sebanyak 33 responden 


\subsection{Metode Analisa Data}

Data yang telah diperolah dari wawancara, observasi dan kuesioner akan diolah dan dianalisa dengan deskriptif kualitatif untuk menggambarkan fenomena yang sebenarnya untuk pengambilan keputusan selanjutnya.

Adapun tahapan analisa data adalah sebagai berikut :

a) Untuk kuesioner yang dibagikan menggunakan skala Likert, yaitu :

1) Jawaban Sangat Setuju diberi skor 5

2) Jawaban Setuju diberi skor 4

3) Jawaban Netral diberi skor 3

4) Jawaban Tidak Setuju diberi skor 2

5) Jawaban Sangat Tidak Setuju diberi skor 1

b) Melakukan uji Validitas dan Reliabilitas agar hasil penelitian mendekati kenyataan dan di percaya.

c) Mengolah dengan analisa deskriptif dengan software SPSS 22

\section{HASIL DAN PEMBAHASAN}

Pembangunan merupakan kegiatan yang tidak dapat terpisahkan dari kehidupan manusia. Pembangunan jalan tol merupakan salah satu dari 3 konsep pembangunan nasional seperti yang tertuang dalam UU No. 15 tahun 2005. Pembangunan jalan tol sendiri merupakan salah satu upaya Pemerintah dalam rangka mewujudkan pemerataan pembangunan di Indonesia. Di antaranya pembangunan jalan tol di Jalur Trans Jawa ( Pemalang- Pekalongan-Semarang). Setiap adanya pembangunan dapat dipastikan akan memberi dampak baik bagi beragam aspek kehidupan diantaranya dunia industri, perhotelan, pariwisata, kuliner dan masyarakat yang ada di sekitarnya. Pekalongan sebagai salah satu Kota di Jawa yang juga terkena dampak pula dengan adanya pembangunan jalan tol ini. Dari beberapa peneliti sebelumnya menunjukkan bahwa dengan adanya jalan tol turut memajukan ekonomi daerah dan mempersibuk kegiatan binis. Adapun dalam penelitian ini dikaji sejauhmana dampak pembangunan jalan tol terhadap dampak sosial, ekonomi dan lingkungan pada usaha batik dan perhotelan di Kota Pekalongan.

Berikut adalah hasil penelitian yang telah dilakukan :

\subsection{Respon Penjual batik dan perhotelan atas pembangunan jalan tol Trans Jawa.}

Berdasarkan hasil wawancara dan pertanyaan terbuka dengan pihak pemilik batik dan pemilik/pengelola hotel di Kota Pekalongan, secara garis besar mereka berpendapat dengan adanya pembangunan jalan tol berdampak negatif karena terjadi adanya penurunan pendapatan, sehubungan dengan itu mereka berharap agar ada upaya-upaya dari Pemerintah. Upaya Pemerintah Kota Pekalongan yang bisa dilakukan salah satunya dengan menyelenggarakan event-event yang bekerja sama dengan dunia industri dan pariwisata agar menarik wisatawan dari luar Kota Pekalongan sehingga harapannya dapat meningkatkan pendapatan baik bagi pedagang batik khususnya, kuliner dan perhotelannya. Di samping itu Pemerintah Kota Pekalongan agar lebih gencar menggalakkan wisata yang ada di Kota Pekalongan dengan melakukan pengelolaan tata kotanya, pengelolaan wisatanya baik kuliner, dan batiknya dengan lebih baik lagi tata kelolanya dengan mempercantik /memperindah lokasinya. 
Selain terkenal dengan kota Batiknya Pekalongan dikenal pula dengan wisata religinya seperti acara Haul / Ziarah ke makam habib, syawalan, dan begitu beragamnya seni, budaya dan wisata yang ada. Pemerintah Kota Pekalongan diharapkan mempromosikan Kota Pekalongan (off line maupun on-line) harapannya agar menjadi peluang pula bagi wisatawan bertandang ke Kota Pekalongan, mengingat dengan adanya pembangunan jalan tol ini memberikan dampak positif pula dalam hal kemudahan akses dan mempercepat perjalanan/transportasi dari satu kota ke kota lain serta jalur tarnsportasi dalam kota Pekalongan tidak terlalu padat sehingga memberikan rasa nyaman dan aman.

\subsection{Dampak Jalan Tol Bagi Usaha Batik}

Sampel dalam penelitian ini diambil di Grosir Setono dan Kampung Batik Hayam Wuruk. Data yang valid untuk diolah sebanyak 44 usaha batik. Dengan menggunakan Skala Likert didapat hasil penelitian sebagai berikut :

Tabel 2 Rekapitulasi Total Jawaban Responden terhadap Dampak Jalan Tol bagi Usaha Batik

\begin{tabular}{|c|cc|c|c|c|c|c|}
\hline NO & FAKTOR & SS & S & N & TS & STS \\
\hline 1 & SOSIAL & & 19 & 78 & 48 & 25 & 6 \\
\hline & & $\%$ & 10,80 & 44,32 & 27,27 & 14,20 & 3,41 \\
\hline 2 & EKONOMI & 7 & 43 & 57 & 56 & 13 \\
\hline & & $\%$ & 3,98 & 24,43 & 32,39 & 31,82 & 7,39 \\
\hline 3 & LINGKUNGAN & 30 & 101 & 34 & 4 & 7 \\
\hline & & $\%$ & 17,05 & 57,39 & 19,32 & 2,27 & 3,98 \\
\hline
\end{tabular}

Dari beberapa respon di atas dapat disimpulkan bahwa secara garis besar dengan dibangunnya jalan tol trans Jawa ini dampak ekonomi memiliki dampak negatif sebesar 31,82\% dari dampak ekonomi sejalan dengan hasil wawancara dan pernyataan terbuka jika terjadi adanya penurunan penjualan. Untuk dampak sosial seperti hubungan dengan suplier bahan batik semakin mudah, akses untuk usaha batik lebih mudah, dan banyak pendatang baru memberikan dampak positif yaitu 44,32\% responden menyatakan setuju. Dampak lingkungan seperti jalan ke lokasi toko batik bebas macet, papan nama usaha batik yang cukup besar, tempat parkir yang luas, juga memberikan dampak positif yaitu sebesar 57,39\% ressponden menyatakan setuju.

\subsection{Dampak Jalan Tol bagi Perhotelan}

Sampel dalam penelitian ini diambil dari perhotelan yang ada di Pekalongan, baik hotel bintang maupun melati. Data yang valid untuk diolah sebanyak 11 hotel. Dengan menggunakan Skala Likert didapat hasil penelitian sebagai berikut :

Tabel 3 Rekapitulasi Total Jawaban Responden terhadap Dampak Jalan Tol bagi Perhotelan

\begin{tabular}{|c|lc|c|c|c|c|c|}
\hline NO & \multicolumn{1}{|c|}{ FAKTOR } & SS & S & N & TS & STS \\
\hline 1 & SOSIAL & 19 & 7 & 8 & 10 & 0 \\
\hline & & $\%$ & 43,18 & 15,91 & 18,18 & 22,73 & 0,00 \\
\hline 2 & EKONOMI & 1 & 14 & 16 & 13 & 0 \\
\hline & & $\%$ & 2,27 & 31,82 & 36,36 & 29,55 & 0,00 \\
\hline 3 & LINGKUNGAN & 18 & 13 & 10 & 2 & 1 \\
\hline & & $\%$ & 40,91 & 29,55 & 22,73 & 4,55 & 2,27 \\
\hline
\end{tabular}

Jika ditinjau dari pengelola hotel maka secara keseluruhan diperoleh gambaran sebagai berikut : dengan dibangunnya jalan tol dampak sosial seperti hubungan antar kota semakin mudah, akses usaha lebih mudah, keamanan dan ketertiban memberikan dampak positif sebesar 43,18\% responden menyatakan sangat setuju. Sedangkan pada dampak lingkungan seperti menarik wisatawan ke Pekalongan, wisatawan lebih mudah mencapai tempat yang dituju dan jalan ke hotel bebas macet mendapat kan 
dampak positif yaitu 40,91\% responden menyatakan sangat setuju. Sedangkan dari faktor ekonomi, mayoritas jawaban responden netral $(36,36 \%)$ cenderung ke arah berdampak negatif dan sebagian merasakan dampak positif. Namun dari kuesioner terbuka didapat hasil 72,7\% responden menyatakan sewa kamar hotel menurun.

\subsection{Dampak Jalan Tol Bagi Pembeli Batik}

Sampel dalam penelitian ini diambil dari responden yang pernah membeli batik di Pekalongan. Data yang valid untuk diolah sebanyak 22 pembeli batik. Dengan menggunakan Skala Likert didapat hasil penelitian sebagai berikut :

Tabel 4 Rekapitulasi Total Jawaban Responden terhadap Dampak Jalan Tol bagi Pembeli Batik

\begin{tabular}{|c|lc|c|c|c|c|c|}
\hline NO & \multicolumn{1}{|c|}{ FAKTOR } & SS & S & N & TS & STS \\
\hline 1 & SOSIAL & 11 & 36 & 32 & 9 & 0 \\
\hline & & $\%$ & 12,50 & 40,91 & 36,36 & 10,23 & 0,00 \\
\hline 2 & EKONOMI & 22 & 69 & 16 & 3 & 0 \\
\hline & & $\%$ & 20,00 & 62,73 & 14,55 & 2,73 & 0,00 \\
\hline 3 & LINGKUNGAN & 9 & 40 & 36 & 3 & 0 \\
\hline & \multicolumn{2}{r|r}{$\%$} & 10,23 & 45,45 & 40,91 & 3,41 & 0,00 \\
\hline
\end{tabular}

Secara keseluruhan pembangunan jalan tol berdampak positif bagi pembeli batik terhadap ke tiga faktor yaitu faktor sosial sebesar 40,91\%, faktor ekonomi sebesar 62,73 dan faktor lingkungan sebesar 45,45\%.

\subsection{Dampak Jalan Tol Bagi Tamu Hotel}

Sampel dalam penelitian ini diambil dari responden yang pernah menginap di Pekalongan. Data yang valid untuk diolah sebanyak 30 tamu hotel. Dengan menggunakan Skala Likert didapat hasil penelitian sebagai berikut :

Tabel 5 Rekapitulasi Total Jawaban Responden terhadap Dampak Jalan Tol bagi Tamu Hotel

\begin{tabular}{|c|lc|c|c|c|c|c|}
\hline NO & \multicolumn{1}{|c|}{ FAKTOR } & SS & S & N & TS & STS \\
\hline 1 & SOSIAL & & 62 & 38 & 17 & 3 & 0 \\
\hline & & $\%$ & 51,67 & 31,67 & 14,17 & 2,50 & 0,00 \\
\hline 2 & EKONOMI & & 60 & 65 & 19 & 5 & 1 \\
\hline & & $\%$ & 40,00 & 43,33 & 12,67 & 3,33 & 0,67 \\
\hline 3 & LINGKUNGAN & 55 & 54 & 8 & 2 & 1 \\
\hline & & $\%$ & 45,83 & 45,00 & 6,67 & 1,67 & 0,83 \\
\hline
\end{tabular}

Dapat disimpulkan pembangunan jalan tol berdampak positif dari faktor sosial $51,67 \%$, faktor ekonomi $43,33 \%$ dan faktor lingkungan sebesar $45,83 \%$ bagi tamu hotel.

\subsection{Dampak Jalan Tol Bagi Masyarakat}

Sampel dalam penelitian ini diambil dari responden yang pernah lewat jalan tol. Data yang valid untuk diolah sebanyak 33 responden. Dengan menggunakan Skala Likert didapat hasil penelitian sebagai berikut :

Tabel 6. Rekapitulasi Total Jawaban Responden terhadap Dampak Jalan Tol bagi Masyarakat

\begin{tabular}{|c|ll|c|c|c|c|c|}
\hline NO & FAKTOR & SS & S & N & TS & STS \\
\hline 1 & SOSIAL & 51 & 51 & 16 & 11 & 3 \\
\hline & & $\%$ & 38,64 & 38,64 & 12,12 & 8,33 & 2,27 \\
\hline 2 & EKONOMI & 41 & 37 & 41 & 38 & 8 \\
\hline & & $\%$ & 24,85 & 22,42 & 24,85 & 23,03 & 4,85 \\
\hline 3 & LINGKUNGAN & 54 & 43 & 20 & 13 & 2 \\
\hline & & $\%$ & 40,91 & 32,58 & 15,15 & 9,85 & 1,52 \\
\hline
\end{tabular}


Secara garis besar dapat diambil kesimpulan bahwa pembangunan jalan tol memiliki dampak yang positif bagi masyarakat, baik dari faktor sosial 38,64\%, Faktor ekonomi sebesar $24,85 \%$ dan faktor lingkungan $40,91 \%$.

Rekomendasi yang dapat diberikan kepada pemerintah yaitu setelah mengetahui dampak negatif terbesar dari pembangunan jalan tol yaitu Dampak Ekonomi, maka perlu dilakukan beberapa langkah langkah untuk menyelamatkan perekonomian khususnya batik dan hotel.

Beberapa rekomendasi yang dapat digunakan sebagai bahan pertimbangan:

a) Akhir akhir ini banyak warga Indonesia yang senang melakukan wisata dan berfoto selfie, dari fenomena ini Pekalongan perlu berbenah diri di bidang Pariwisata. Hal yang perlu dilakukan yaitu dengan memperbaiki dan memperindah wisata dan promosi wisata secara gencar.

b) Dari beberapa pengamatan kegiatan di Pekalongan, wisata religi termasuk kegiatan yang dapat mendatangkan pengunjung dari berbagai daerah, untuk itu wisata religi ini perlu mendapat perhatian.

c) Perlu diadakan kegiatan atau even even besar yang mampu mendatangkan pengunjung dari daerah lain atau kegiatan yang bersifat nasional.

d) Perlu dibangunnya tugu canting atau landmark atau baliho besar di jalan masuk ke Kota Pekalongan yang mampu mengarahkan pengunjung untuk mampir di Pekalongan

\section{KESIMPULAN DAN SARAN}

\subsection{Kesimpulan}

a) Dampak Ekonomi sangat dirasakan oleh usaha batik di Pekalongan. 31,82\% responden menyatakan penurunan penjualan, sedangkan Faktor sosial dan lingkungan memberikan dampak positif bagi usaha batik Pekalongan.

b) Perhotelan di Pekalongan sebagian terkena dampak ekonomi dan sebagian tidak, hal ini terlihat jawaban netral / ragu sebesar 36,36\%. Namun dari kuesioner terbuka $72,7 \%$ responden menyatakan penurunan sewa kamar. Sedangkan faktor sosial dan lingkungan memberikan dampak positif bagi usaha Perhotelan di Pekalongan

c) Bagi tamu hotel, pembeli batik dan masyarakat Pekalongan, pembangunan jalan tol memberikan dampak positif bagi mereka.

\subsection{SARAN}

a) Guna menangani dampak ekonomi akibat pembangunan jalan tol ini, perlu diadakan pelatihan-pelatihan untuk hotel atau usaha batik di bidang marketing online.

b) Perlunya sinergi dalam promosi Batik, Hotel dan Pariwisata.

\section{DAFTAR PUSTAKA}

Adisasmita. (2012). Perencanaan Infrastruktur Transportasi Wilayah. Yogyakarta : Graha Ilmu

Dhony Priyo Suseno. (2017). Analisis Dampak Jalan tol Terhadap Faktor sosial, Ekonomi dan Lingkungan di Desa Kaligangsa Kulon Kabupaten Brebes. Prosiding SNST ke 8. 
Egi Loveyan Jaya. (2018). Dampak Pembangunan Jalan Tol Bakauheni -Terbanggi Besar Terhadap Kehidupan Sosial Ekonomi Penduduk Sekitar Gerbang Tol di Kelurahan Korpri Raya Kota Bandar Lampung, Skripsi, Universitas Lampung Bandar Lampung.

Eko Irianto. (2010). Analisis Dampak rencana Pembangunan Jalan Tol di Kabupaten Batang terhadap Faktor Sosial Ekonomi dan Lingkungan, Tesis. Semarang : Universitas Islam Sultan Agung.

Kompasiana. (2019). Dampak Tol Trans Jawa bagi Kota Pantura. http://www.kompasiana.com/ilvani/5c1323b812ae9462815d8c13, 16 April 2019.

Triana Rosalina Noor. Analisis Dampak Sosial Ekonomi Pembangunan Jalan Tol SurabayaMojokerto. Banyuwangi: Prosiding Seminar Nasional dan Temu Ilmiah jaringan Peneliti IAI Darussalam Blok Agung, n.d.

Uswatun Khasanah. (2017). Dampak Pembangunan Jalan Tol Solo-Kertosono Terhadap Hak Ekonomi Masyarakat Desa Kasreman Kecamatan Geneng Kabupaten Ngawi, Citizenship Jurnal Pancasila dan Kewarganegaraan

Victorianus Aries Siswanto. (2015). Belajar Sendiri SPSS 22. Yogyakarta : Andi Offset.

Victorianus Aries Siswanto. (2012). Strategi dan Langkah-langkah penelitian. Yogyakarta: Graha Ilmu. 